\title{
Comportamento ingestivo de novilhas Pantaneiras mantidas em regime de confinamento
}

\author{
Feeding behavior of Pantaneiras heifers kept in feedlot
}

\author{
OLIVEIRA, Marcus Vinicius Morais de ${ }^{1}$; RUFINO JUNIOR, João ${ }^{1}$; ROMERO, \\ Jakeline Vieira $^{2}$; SILVA, Diogo Cesar Gomes da ${ }^{1}$; LUZ, Dirce Ferreira ${ }^{3}$; VARGAS \\ JUNIOR, Fernando Miranda de ${ }^{4}$; FERNANDES, Henrique Jorge ${ }^{1}$, SALLA, Luciane \\ Elisete $^{1 *}$
}

\footnotetext{
${ }^{1}$ Universidade Estadual de Mato Grosso do Sul, Aquidauana, Mato Grosso do Sul, Brasil.

${ }^{2}$ Universidade de Cuiabá, Cuiabá, Mato Grosso, Brasil.

${ }^{3}$ Universidade Federal de Mato Grosso do Sul, Aquidauana, Mato Grosso do Sul, Brasil.

${ }^{4}$ Universidade Federal da Grande Dourados, Dourados, Mato Grosso do Sul, Brasil.

*Endereço para correspondência: lusalla@yahoo.com.br
}

\section{RESUMO}

Objetivou-se avaliar o comportamento ingestivo de novilhas da raça Pantaneira (Bos taurus taurus) confinadas e alimentadas com diferentes tipos de feno e ração concentrada, com uma relação na matéria seca de 60:40\%, respectivamente. Quinze animais, com peso médio inicial de $298 \mathrm{~kg}$ e idade de 30 meses, foram distribuídos em um delineamento inteiramente casualizado, em três lotes, com cinco repetições. Os fenos utilizados foram: feno de Brachiaria brizantha cv. Piatã, feno de Panicum maximum cv. Massai, e feno de Stylosantes capitata/macrocephala cv. Campo Grande. Todas as dietas possuíam teores energéticos e proteicos semelhantes, de $63,3 \%$ de nutrientes digestíveis totais (NDT) e $12,5 \%$ de proteína bruta (PB), e eram fornecidas duas vezes ao dia, à vontade. As observações de comportamento ingestivo foram efetuadas em três baterias de 48 horas cada, em intervalos de 28 dias, totalizando 144 horas. Os dados foram interpretados por meio de análise de variância e teste de Tukey. Não foram observadas influências das forrageiras nos tempos de alimentação, ruminação, ócio, interagindo e dormindo, tampouco nas eficiências de alimentação e de ruminação, na ingestão de água e nas excreções de urina e fezes, sendo todas as variáveis estatisticamente iguais. A utilização de qualquer um dos tipos de feno na dieta de novilhas Pantaneiras é recomendada.

\section{SUMMARY}

The objective this work was to evaluate the intake and physiological behavior of heifers of the Pantaneira (Bos Taurus taurus) breed, feedlot and fed with different types of hay and concentrate, in a ratio in dry matter of 60:40 \%, respectively. Fifteen animals, with an average initial weight of $298 \mathrm{~kg}$ and 30 months of age, were distributed through completely randomized design in three batches, with five replicates. The hays were: hay of Brachiaria brizantha cv. Piata, hay of Panicum maximum cv. Massai, and hay of leguminous Stylosantes capitata/macrocephala cv. Campo Grande. All diets had similar energy and protein content of $63.3 \%$ Total Digestible Nutrients (TDN) and 12.5\% Crude Protein (CP) and were fed twice a day, ad libitum. The observations of ingestive behavior and physiology were made in three batteries of 48 hours each, an interval of 28 days, totaling 144 hours. The data were interpreted by analysis of variance and Tukey test. There weren't influences of forage in feeding times, rumination, sleeping and interacting; efficiencies in feeding and rumination, water intake and excretion in urine and feaces, and all variables are statistically similar. Therefore, the use of either type of hay in the diet is recommended Pantaneiras heifers.

Keywords: ethology, hay, nutrients, livestock

Palavras-chave: etologia, feno, nutrientes, pecuária 
Rev. Bras. Saúde Prod. Anim., Salvador, v.16, n.3, p.688-698 jul./set.., 2015 http://www.rbspa.ufba.br

\section{INTRODUÇÃO}

Animais Pantaneiros caracterizam-se por serem indivíduos de pequeno porte, porém de grande rusticidade, principalmente nas características relacionadas à capacidade de suportar elevadas temperaturas ambientais, períodos de seca e alagamento intermitentes, ecto e endoparasitas e variações sazonais na qualidade dos recursos forrageiros disponíveis.

Apesar de, no passado, o rebanho de bovinos pantaneiros somar milhões de cabeças (SANTOS et al., 2005), atualmente, esta raça, genuinamente brasileira, encontra-se em risco de extinção, com cerca de 500 indivíduos puros, criados em algumas fazendas e núcleos de conservação (DANI \& OLIVEIRA, 2013). Assim, estudos sobre os animais da raça Pantaneira são vitais para se conhecer o seu potencial zootécnico e, consequentemente, evitar a perda deste recurso genético altamente adaptado à região do Pantanal.

Neste âmbito, o estudo do comportamento animal é uma ferramenta interessante para se investigar as mudanças dos padrões comportamentais, especialmente acerca do comportamento ingestivo, uma vez que esta variável pode interferir no desempenho dos animais. Segundo Carvalho et al. (2008), o comportamento ingestivo é altamente influenciado pela qualidade nutricional do alimento e pela necessidade fisiológica dos animais, bem como pelo estresse, doenças e parasitas .

Cada espécie animal constitui seu próprio repertório peculiar de padrões de comportamento alimentar, particularidades anatômicas, etc. Portanto, estes fatores determinam os padrões, a duração e a quantidade de alimentos consumidos e, como consequência, a qualidade do que é selecionado para ser ingerido. Logo, em se tratando de animais Pantaneiros, poucos trabalhos foram, até então, investigados, sobretudo no que tange a sistemas produtivos com animais confinados.

Assim, objetivou-se avaliar o comportamento ingestivo de novilhas da raça Pantaneira mantidas em regime de confinamento, recebendo diferentes tipos de feno como volumosos.

\section{MATERIAL E MÉTODOS}

O experimento foi conduzido no Núcleo de Bovinos Pantaneiros de Aquidauana (NUBOPAN), pertencente à Universidade Estadual de Mato Grosso do Sul (UEMS), em Aquidauana/MS, região do Alto Pantanal Sul-MatoGrossense, nas coordenadas: altitude $181 \mathrm{~m}$, latitude $20^{\circ} 28^{\prime}$ Sul e longitude $55^{\circ} 47^{\prime}$ Oeste, entre os meses de maio a setembro, período de outono-inverno.

Foram utilizadas quinze novilhas Pantaneiras (Bos taurus taurus), com idade média de 30 meses e peso corpóreo (PC) inicial médio de $298 \pm 19,2 \mathrm{Kg}$, mantidas em regime de confinamento por 114 dias, sendo os 30 primeiros para adaptação às instalações, ao manejo e à dieta, e os outros 84 , divididos em três períodos de 28 dias.

No inicio do ensaio, as novilhas foram separadas em três lotes de cinco animais, em um delineamento inteiramente casualizado e, em seguida, alocadas nos tratamentos contendo diferentes espécies forrageiras, em uma relação volumosoconcentrado, na matéria seca, de 60:40\%, respectivamente. Como volumoso, foram utilizados os fenos de capim braquiária (Brachiaria brizantha) cv. Piatã, de capim colonião (Panicum maximum) cv. Massai e da leguminosa estilosantes 
Rev. Bras. Saúde Prod. Anim., Salvador, v.16, n.3, p.688-698 jul./set.., 2015 http://www.rbspa.ufba.br ISSN 15199940 http://dx.doi.org/10.1590/S1519-99402015000300019

(Stylosantes capitata macrocephala) cv. Campo Grande. Os fenos foram reduzidos a $\pm 3 \mathrm{~cm}$ de comprimento, utilizando-se um picador de forragem. O concentrado era composto por milho, farelo de soja, sal mineral, ureia e calcário.

As dietas apresentaram teores energético e proteico semelhantes, de $63,3 \%$ de nutrientes digestíveis totais (NDT) e $12,5 \%$ de proteína bruta (PB), e foram fornecidas duas vezes ao dia, às $7 \mathrm{~h} 00$ e às $16 \mathrm{~h} 00$, proporcionando uma sobra, na matéria natural, de aproximadamente $10 \%$.

As análises bromatológicas dos ingredientes foram realizadas no laboratório de Bromatologia da Universidade de Cuiabá (UNIC), onde, para as determinações dos teores de matéria seca (MS), matéria mineral $(\mathrm{MM})$, proteína bruta (PB) e extrato etéreo (EE), utilizou-se a metodologia conforme Silva \& Queiroz (2002). Para a determinação da fibra em detergente neutro (FDN) e fibra em detergente ácido (FDA), utilizou-se autoclave, onde $0,5 \mathrm{~g}$ de amostra, acondicionada em sacos de tecidos não-tecidos (TNT), previamente secos e pesados, foram fervidos por uma hora em solução de detergente neutro, utilizando $\alpha$-amilase (VAN SOEST \& ROBERTSON, 1985), lavados com água quente e acetona, secos e pesados, sendo o seu resíduo considerado a FDN. Para a FDA, adotou-se o mesmo procedimento, mas com solução de detergente ácido. O NDT foi calculado conforme metodologia Undersander et al. (1993) \& Kearl (1982).

Os resultados das análises, bem como a composição das dietas experimentais, estão descritas nas Tabelas 1 e 2, respectivamente. As novilhas permaneceram confinadas em um galpão de alvenaria, com pé direito de 4 metros e telhas de barro. As baias eram individuais, com $2,2 \times 4,0 \mathrm{~m}^{2}$, providas de cocho e bebedouro automático, com laterais feitas com cordoalha de aço e $70 \%$ do piso revestido com concreto e $30 \%$ de terra, coberta semanalmente com palha de arroz, para aumentar o conforto e eliminar a umidade. Antes de iniciar o período experimental, os animais foram preventivamente vermifugados e banhados com carrapaticida e receberam uma dose intramuscular das vitaminas A, D e E.

Tabela 1. Teores de matéria seca (MS), proteína bruta (PB), nutrientes digestíveis totais (NDT), fibra em detergente neutro (FDN), fibra em detergente ácido (FDA), extrato etéreo (EE) e matéria mineral (MM) dos ingredientes utilizados nas dietas

\begin{tabular}{lccccccc}
\hline Variáveis & $\mathrm{MS}^{1}$ & $\mathrm{~PB}^{2}$ & $\mathrm{NDT}^{23}$ & $\mathrm{FDN}^{2}$ & $\mathrm{FDA}^{2}$ & $\mathrm{EE}^{2}$ & $\mathrm{MM}^{2}$ \\
\hline Feno de Piatã & 87,07 & 4,76 & 51,62 & 79,19 & 42,31 & 1,03 & 4,36 \\
Feno de Massai & 85,64 & 4,32 & 51,48 & 80,97 & 42,93 & 1,09 & 4,23 \\
Feno de Estilosantes & 86,43 & 8,49 & 50,95 & 72,97 & 47,46 & 1,24 & 2,76 \\
Grão de milho triturado & 88,64 & 8,52 & 85,00 & 15,30 & 2,45 & 3,51 & 1,51 \\
Farelo de soja & 90,32 & 52,90 & 82,00 & 10,46 & 4,61 & 6,01 & 6,25 \\
Ureia & 98,00 & 281,0 & - & - & - & - & - \\
Sal mineral & 100,00 & - & - & - & - & - & 100,00 \\
Calcário calcítico & 100,00 & - & - & - & - & - & 100,00 \\
\hline
\end{tabular}

${ }^{1}$ Expressos em \% matéria natural; ${ }^{2}$ Expressos na matéria seca; ${ }^{3}$ Valadares Filho et al. (2006). 
Rev. Bras. Saúde Prod. Anim., Salvador, v.16, n.3, p.688-698 jul./set.., 2015 http://www.rbspa.ufba.br

Tabela 2. Composição percentual e teores de proteína bruta (PB), nutrientes digestíveis totais estimados (NDT estimados), fibra em detergente neutro (FDN) e fibra em detergente ácido (FDA) das dietas, expressos na matéria seca

\begin{tabular}{lccc}
\hline \multirow{2}{*}{ Ingredientes } & \multicolumn{3}{c}{ Forrageiras } \\
\cline { 2 - 4 } & Piatã & Massai & Estilosantes \\
\hline Feno de Piatã & 60,00 & - & - \\
Feno de Massai & - & 60,00 & - \\
Feno de Estilosantes & - & - & 60,00 \\
Grão de Milho triturado & 27,00 & 26,60 & 32,30 \\
Farelo de Soja & 11,50 & 11,90 & 6,20 \\
Ureia & 0,50 & 0,50 & 0,50 \\
Sal Mineral ${ }^{1}$ & 0,80 & 0,80 & 0,80 \\
Calcário Calcítico & 0,20 & 0,20 & 0,20 \\
Total & 100,00 & 100,00 & 100,00 \\
\hline Proteína Bruta (PB) & 12,60 & 12,60 & 12,50 \\
Nutrientes Digestíveis Totais (NDT) & 63,30 & 63,30 & 63,10 \\
Fibra em Detergente Neutro (FDN) & 49,90 & 49,80 & 45,40 \\
Fibra em Detergente Ácido (FDA) & 26,20 & 25,50 & 27,30 \\
\hline
\end{tabular}

${ }^{1}$ Cálcio: 120g; Fósforo: 88g; Sódio: 132g; Enxofre: 12g; Cobalto: 55mg; Cobre: 1.530mg; Cobre: 1.800mg; Iodo: 75mg; Manganês: 1.300mg; Selênio: 15mg; Zinco: 3.630mg; Cromo: 10mg; Flúor: 880mg; Fosforilato base: $100 \mathrm{~g}$.

As observações referentes ao comportamento ingestivo ocorreram de forma visual, a intervalos de cinco minutos, pelo método de varredura instantânea (MORAIS et al., 2006) com início as 06:00 horas da manhã, durante três períodos de 48 horas, a cada 28 dias, totalizando 144 horas de coletas. Iluminação artificial noturna foi fornecida durante todo o período experimental. Foi observado, também, o número de vezes que os animais beberam água, bem como o número de vezes nas atividades de defecação e micção, conforme metodologia de Carvalho et al. (2006). Os dados foram tabulados em planilhas apropriadas para ensaios de comportamento para que não houvesse dúvidas sobre as observações. Os dados foram coletados por observadores treinados, sendo dois de cada vez, em sistema de revezamento, posicionados estrategicamente, de forma a não interferir no comportamento habitual dos animais. As variáveis investigadas para o comportamento ingestivo foram: tempo de ruminação, tempo de ócio, tempo dormindo, tempo de alimentação e tempo interagindo.

As eficiências de alimentação e ruminação em função da matéria seca (MS), da proteína bruta (PB) e da fibra em detergente neutro (FDN) foram calculadas de acordo com as seguintes equações adaptadas de Bürger et al. (2000), onde: $\mathrm{EAMS}=\mathrm{CMS} / \mathrm{TA}(\mathrm{kg}$ $\mathrm{MS} / \mathrm{h}$ ) - eficiência de alimentação em função do CMS; ERMS = CMS/TR (kg MS/h) - eficiência de ruminação em função do CMS; EAPB = CPB/TA (kg PB/h) - eficiência de alimentação em função do CPB; ERPB = CPB/TR $(\mathrm{kg} \mathrm{PB} / \mathrm{h})$ - eficiência de ruminação em função do CPB; EAFDN = CFDN/TA ( $\mathrm{kg}$ FDN/h) - eficiência de alimentação em função do $\mathrm{CFDN}$; $\mathrm{ERFDN}=\mathrm{CFDN} / \mathrm{TR}(\mathrm{kg} \mathrm{FDN} / \mathrm{h})-$ eficiência de ruminação em função do CFDN, sendo: CMS (kg MS/dia) - 
consumo de matéria seca; TA (h/dia) tempo de alimentação; TR (h/dia) tempo de ruminação Total; CPB $(\mathrm{kg}$ $\mathrm{PB} /$ dia) - consumo de proteína bruta; CFDN (kg FDN/dia) - consumo de fibra em detergente neutro.

Os dados experimentais foram interpretados por meio de análise de variância e teste de Tukey ao nível de $5 \%$ de probabilidade, segundo o modelo estatístico: yij $=\mathrm{m}+\mathrm{ti}+$ eij, em que: $\mathrm{m}=$ constante geral; $\mathrm{ti}=$ efeito do suplemento i, sendo $\mathrm{i}=\mathrm{um}$, dois, três e quatro; eij = erro aleatório associado a cada observação, pressuposto NID $\left(0, s^{2}\right)$. Foi utilizado o sistema de análise estatística e genética - SAEG (UFV, 2007).

\section{RESULTADOS E DISCUSSÃO}

Não houve diferença de consumo entre os nutrientes estudados (Tabela 3), para os variados tipos de fenos ofertados aos animais $(\mathrm{P}<0,05)$. No entanto, apesar de $\mathrm{o}$ feno do estilosantes apresentar menores quantidades de FDN e maiores de PB (Tabela 1), o mesmo não foi suficiente para elevar o consumo por parte das novilhas, já que, a composição da dieta foi muito semelhante (Tabela 2). É sabido que níveis de $\mathrm{PB}$ aumentados na dieta, levam a um aumento no coeficiente de digestibilidade da FDN, sugerindo um maior aporte de nitrogênio aos microrganismos ruminais, melhorando assim, a degradação da fibra e o consumo, portanto, não verificados no presente estudo.

Os tempos de alimentação, ruminação, ócio, interagindo e dormindo, expressos em minutos por dia, não foram influenciados estatisticamente $(\mathrm{P}>0,05)$ pelos diferentes tipos de fenos fornecidos (Tabela 4), indicando a elevada capacidade adaptativa dos bovinos pantaneiros em aproveitar alimentos altamente fibrosos. Apesar de serem animais domésticos, as novilhas da raça Pantaneira, provavelmente, herdaram de seus ancestrais remotos, algumas características comportamentais que são vitais para a sua sobrevivência no Pantanal, como é o caso do comportamento alimentar peculiar (CORREA- CALDERÓN et al., 2009), refletindo, assim, em um aproveitamento maior da fibra da dieta. Já que o consumo de MS e de FDN dos diferentes volumosos utilizados mostrou valores semelhantes, assim, o tempo de alimentação também não variou. Dessa forma, Alves et al. (2010), propuseram que a semelhança no consumo para as diferentes dietas pode ser um fator que contribui para a não diferenciação no tempo de alimentação e de ruminação.

Observa-se que, no período diurno (06:00 às 18:00 horas), o tempo de alimentação foi de $191,05 \mathrm{~min} / \mathrm{dia} \mathrm{e}$, durante o período noturno (18:00 às 06:00 horas), de 41,17 min/dia (Tabela 5). Essas diferenças, observadas quanto ao tempo de alimentação, justificam-se pelo fato do alimento ter sido ofertado durante o dia, sendo, portanto, coerente que nesse período fosse despendido maior tempo para alimentação em relação à ruminação e ao ócio, pois o fornecimento da ração induz o animal a ingerir; resultados comprovados por Fotius et al. (2014) \& Chagas et al. (2015). 
Rev. Bras. Saúde Prod. Anim., Salvador, v.16, n.3, p.688-698 jul./set.., 2015 http://www.rbspa.ufba.br ISSN 15199940 http://dx.doi.org/10.1590/S1519-99402015000300019

Tabela 3. Consumos de matéria seca e de nutrientes em novilhas da raça Pantaneira, recebendo diferentes tipos de fenos

\begin{tabular}{|c|c|c|c|c|c|c|}
\hline \multirow{2}{*}{ Variáveis ${ }^{1}$} & \multicolumn{3}{|c|}{ Forrageiras } & \multirow{2}{*}{$\begin{array}{c}\text { Erro } \\
\text { Padrão }\end{array}$} & \multirow{2}{*}{$\mathrm{CV}$} & \multirow{2}{*}{ Média } \\
\hline & Piatã & Massai & Estilosantes & & & \\
\hline Matéria Seca - kg & 7,11 & 6,60 & 6,61 & 0,28 & 15,92 & 6,77 \\
\hline CMSPC (kg MS/100 kg PC) & 2,22 & 2,10 & 2,08 & 0,79 & 14,40 & 2,13 \\
\hline CMSPM (g MS/PC $\left.{ }^{0,75}\right)$ & 93,86 & 88,42 & 87,92 & 3,30 & 14,19 & 90,07 \\
\hline Proteína Bruta - kg & 1,21 & 1,10 & 1,07 & 1,13 & 15,51 & 1,13 \\
\hline Fibra Detergente Neutro - kg & 3,40 & 3,13 & 2,88 & 3,14 & 20,31 & 3,14 \\
\hline Fibra Detergente Ácido - kg & 1,76 & 1,66 & 1,79 & 1,74 & 18,29 & 1,74 \\
\hline
\end{tabular}

${ }^{1}$ Médias seguidas de letras diferentes, na linha, diferem entre si $(\mathrm{P}<0,05)$ pelo teste Tukey.

$\mathrm{CMSPC}=$ consumo matéria seca em função do peso corporal; $\mathrm{CMSPM}=$ consumo matéria seca em função do peso metabólico.

Tabela 4. Comportamento ingestivo de novilhas da raça Pantaneira alimentadas com diferentes tipos de fenos

\begin{tabular}{|c|c|c|c|c|c|}
\hline \multirow{2}{*}{ Variáveis } & \multicolumn{3}{|c|}{ Fenos $^{1}$} & \multirow{2}{*}{$\begin{array}{l}\text { CV } \\
(\%)\end{array}$} & \multirow{2}{*}{$\begin{array}{c}\text { Média } \\
\text { (Min/dia }\end{array}$} \\
\hline & Piatã & Massai & Estilosantes & & \\
\hline Tempo de Alimentação (Min/dia) & 233,50 & 222,83 & 240,33 & 19,40 & 232,22 \\
\hline Tempo de Ruminação (Min/dia) & 446,83 & 409,50 & 460,67 & 7,88 & 439,00 \\
\hline Tempo de Ócio (Min/dia) & 430,00 & 455,67 & 381,67 & 14,40 & 422,44 \\
\hline Tempo Interagindo (Min/dia) & 177,83 & 167,33 & 173,17 & 17,26 & 172,78 \\
\hline Tempo Dormindo (Min/dia) & 155,17 & 184,67 & 184,17 & 25,81 & 174,67 \\
\hline
\end{tabular}

${ }^{1}$ Não foram detectadas diferenças significativas pelo Teste $\mathrm{F}$ à $5 \%$ de probabilidade.

Tabela 5. Médias dos tempos de atividades comportamentais (ingestivas) nos períodos de dia (06:00 às 18:00 horas) e noite (18:00 às 06:00 horas) de novilhas da raça Pantaneira

\begin{tabular}{lrrr}
\hline \multirow{2}{*}{ Variáveis } & \multicolumn{2}{c}{ Comportamento (Min) } \\
\cline { 2 - 4 } & Total & Dia & Noite \\
\hline Tempo de Alimentação (Min/dia) & 232,22 & 191,05 & 41,17 \\
Tempo de Ruminação (Min/dia) & 439,00 & 158,00 & 281,00 \\
Tempo de Ócio (Min/dia) & 422,44 & 200,66 & 221,78 \\
Tempo Interagindo (Min/dia) & 172,78 & 125,83 & 46,95 \\
Tempo Dormindo (Min/dia) & 174,67 & 41,50 & 133,17 \\
\hline
\end{tabular}

$\mathrm{MIN} / \mathrm{dia}=$ minuto $/ \mathrm{dia}$.

Os animais consomem por pequenos espaços de tempo, cada um destes caracterizando uma refeição, sendo que o número de refeições diárias varia de espécie para espécie e apresenta distribuição irregular ao longo das 24 horas, havendo preferência das espécies domésticas pela alimentação diurna
(SILVA et al., 2005). Segundo Marques et al. (2005), o tempo total de ruminação pode variar de quatro a nove horas, sendo dividido em períodos de poucos minutos a mais de uma hora.

Em relação à ruminação, esta é influenciada pelo período do dia e pelo alimento, sendo mais prolongada 
Rev. Bras. Saúde Prod. Anim., Salvador, v.16, n.3, p.688-698 jul./set.., 2015 http://www.rbspa.ufba.br ISSN 15199940 http://dx.doi.org/10.1590/S1519-99402015000300019

durante a noite, como pode ser observado (Tabela 5).

No entanto, é prudente não desconsiderar que existem diferenças entre os animais quanto à duração e à repartição das atividades de ingestão e de ruminação, que podem estar relacionadas ao apetite, diferenças anatômicas e ao suprimento das exigências energéticas ou enchimento ruminal (SOUZA et al., 2007).

A eficiência alimentar (EAL) e a eficiência de ruminação (ER), em função da matéria seca, da proteína bruta e da fibra em detergente neutro, não apresentaram diferenças significativas $(\mathrm{P}>0,05)$, com médias de $1,78 \mathrm{~kg} \mathrm{MS} / \mathrm{h}, 0,29 \mathrm{~kg} \mathrm{~PB} / \mathrm{h}$ e $0,83 \mathrm{~kg}$ $\mathrm{FDN} / \mathrm{h}$ para a $\mathrm{EAL}$ e $0,93 \mathrm{~kg} \mathrm{MS} / \mathrm{h}$, $0,15 \mathrm{kgPB} / \mathrm{h}$ e $0,43 \mathrm{~kg} \mathrm{FDN} / \mathrm{h}$ para a ER, respectivamente (Tabela 6). As dietas testadas eram ricas em fibras, com proporção, na matéria seca, de 60:40\% de

volumoso-concentrado, respectivamente. Logo, infere-se que os elevados teores médios de FDN $(77,7 \%$, na MS) e de FDA $(44,2 \%$, na MS) (Tabela 2) das dietas experimentais e a semelhança entre elas foram os responsáveis por este resultado. Diferenças esperadas sobre as eficiências poderiam ocorrer se $\mathrm{o}$ nível de fibra da dieta fosse distinto, uma vez que, a eficiência de ruminação é aumentada quando se aumenta o nível de fibra na dieta (CARDOSO et al., 2006; MISSIO et al., 2010), o que não foi o caso do presente estudo. Em contrapartida, Pinto et al. (2010) ressaltaram que esse fato não é observado quando se avalia a eficiência de ruminação da parede celular, sendo que as dietas do presente estudo, com a utilização de diferentes tipos de fenos, não diferiram $(\mathrm{P}>0,05)$, possivelmente devido a ausência de diferença quanto a ingestão de FDN das dietas, como já mencionado.

Tabela 6. Eficiências de alimentação e de ruminação, da matéria seca, da proteína bruta e da fibra em detergente neutro de novilhas da raça Pantaneira alimentadas com diferentes tipos de fenos

\begin{tabular}{|c|c|c|c|c|c|}
\hline \multirow{2}{*}{ Variáveis } & \multicolumn{3}{|c|}{ Forrageiras $^{1}$} & \multirow{2}{*}{ CV $(\%)$} & \multirow{2}{*}{ Média (Kg MS/dia) } \\
\hline & Piatã & Massai & Estilosantes & & \\
\hline \multicolumn{6}{|c|}{ Eficiência de Alimentação } \\
\hline EALMS (kg MS/h) & $1,891,78$ & 1,66 & 1,66 & 13,04 & 1,78 \\
\hline EALPB $(\mathrm{kg} \mathrm{PB} / \mathrm{h})$ & $0,320,29$ & 0,26 & 0,26 & 20,26 & 0,29 \\
\hline EALFDN (kg FDN/h) & 0,92 & 0,84 & 0,72 & 24,02 & 0,83 \\
\hline \multicolumn{6}{|c|}{ Eficiência de Ruminação } \\
\hline ERMS (kg MS/h) & 0,95 & 0,97 & 0,86 & 14,87 & 0,93 \\
\hline ERPB (kg PB/h) & 0,16 & 0,16 & 0,14 & 12,81 & 0,15 \\
\hline ERFDN (kg FDN/h) & 0,45 & 0,45 & 0,38 & 16,85 & 0,43 \\
\hline
\end{tabular}

${ }^{1}$ Não foram detectadas diferenças significativas pelo Teste $\mathrm{F}$ à $5 \%$ de probabilidade.

EALMS = eficiência de alimentação em função do consumo de matéria seca; ERMS = eficiência deruminação em função do consumo de matéria seca; EAFDN = eficiência de alimentação em função do consumo de fibra em detergente neutro; ERFDN = eficiência de ruminação em função do consumo de fibra em detergente neutro; EAPB = eficiência de alimentação em função do consumo de proteína bruta; ERPB = eficiência de ruminação em função do consumo de proteína bruta.

Marques et al. (2005), trabalhando com comportamento ingestivo de bovinos e bubalinos, observaram médias de $2,23 \mathrm{~kg}$
$\mathrm{MS} / \mathrm{h}$ e $0,59 \mathrm{~kg} \mathrm{FDN} / \mathrm{h}$, para EALFDN, e de $1,28 \mathrm{~kg} \mathrm{MS} / \mathrm{h}$ e $1,02 \mathrm{~kg} \mathrm{FDN} / \mathrm{h}$, para ERFDN, diferentes, portanto dos valores 
Rev. Bras. Saúde Prod. Anim., Salvador, v.16, n.3, p.688-698 jul./set.., 2015 http://www.rbspa.ufba.br

encontrados para os bovinos da raça Pantaneira. As variações entre os experimentos de literatura podem ser compreendidas pelos diferentes grupamentos genéticos, idade dos animais e pelas variações na qualidade nutricional das dietas, em especial, nas concentrações de FDN e FDA.

Magalhães et al. (2012) também não encontraram diferenças para eficiência de alimentação e de ruminação e reiteraram que esta ausência do efeito, observada para as respectivas atividades, pode estar relacionada com a aproximação entre a composição química das dietas, bem como a semelhança entre o tamanho de partículas dos alimentos. Argumentos confirmados por Van Soest (1994), nos quais o tamanho da partícula pode ser um fator nutricional importante que influencia o valor nutricional do alimento, que, por sua vez, afeta tanto o consumo de MS, como a retenção ruminal, exercendo, assim, grande efeito sobre as atividades de alimentação e de ruminação (SAENZ, 2005). Da mesma forma, Silva et al. (2005) afirmaram que a eficiência de ruminação do alimento é afetada positivamente pela elevação da matéria seca da dieta.

Não foi observada nenhuma diferença significativa $\quad(\mathrm{P}>0,05)$ entre os tratamentos, para os parâmetros de números de ingestão de água, excreção de urina e de fezes, com médias de 7,59; 6,40 e 7,97 vezes ao dia (Tabela 7). Isto Indica que qualquer um dos volumosos utilizados não influenciou na procura por água pelos animais. A semelhança entre as frequências de busca por água pode ser explicada pelo fato de os animais estarem submetidos às mesmas condições ambientais e a dietas fisicamente semelhantes. Quanto à frequência de micção, não havendo diferença no consumo de água para as diferentes dietas, é compreensível que este fator também não tenha sido afetado. Por não ter ocorrido diferença de consumo de matéria seca e de FDN (Tabela 3), também já era esperado que, entre as dietas experimentais, não houvesse diferenças para as frequências de defecação, resultados estes, em acordo com Miotto et al. (2014).

Tabela 7. Comportamento de ingestão e excreção de novilhas da raça Pantaneira, alimentadas com diferentes tipos de fenos

\begin{tabular}{|c|c|c|c|c|c|}
\hline \multirow{3}{*}{ Variáveis } & \multicolumn{3}{|c|}{ Forrageiras $^{1}$} & \multirow{2}{*}{$\begin{array}{l}\mathrm{CV} \\
(\%)\end{array}$} & \multirow{2}{*}{$\begin{array}{c}\text { Média } \\
\left(\mathrm{n}^{\mathrm{o}} \text { vezes/dia) }\right.\end{array}$} \\
\hline & Piatã & Massai & Estilosantes & & \\
\hline & \multicolumn{5}{|c|}{ Comportamento Fisiológico } \\
\hline Ingestão de Água (nº de vezes/dia) & 8,67 & 7,07 & 7,03 & 39,32 & 7,59 \\
\hline Excreção de Urina (no de vezes/dia) & 8,20 & 5,73 & 5,27 & 19,85 & 6,40 \\
\hline Excreção de Fezes (n ${ }^{\circ}$ de vezes/dia) & 9,43 & 7,80 & 6,67 & 30,57 & 7,97 \\
\hline
\end{tabular}

${ }^{1}$ Não foram detectadas diferenças significativas pelo Teste $\mathrm{F}$ à $5 \%$ de probabilidade.

A frequência de micção, segundo Degasperi et al. (2003), pode variar de quatro a 10 vezes por dia, confirmando, assim, estas frequências observadas no presente estudo. Vale ressaltar que a micção está intimamente relacionada com a ingestão de água, sendo, esta, oriunda do alimento ou do próprio consumo. Arnaud et al. (2005) verificaram micção (média geral de 10,48 no vezes/dia de ingestão de água) por vacas holandesas em lactação. Logo, vacas em lactação têm um consumo superior de água a outras 
categorias animais devido à demanda para a produção de leite. Portanto, é justificável o fato de novilhas não lactantes apresentarem um menor número de micções.

Este estudo demonstra que os volumosos utilizados não afetaram a excreção de água pelos animais, sendo que, aqueles, justificam a não diferença no consumo de água destes, já que, segundo Nascimento et al. (2013), esta variável dependerá da quantidade de água no alimento ingerido, da temperatura, da umidade ambiental, do exercício e do estado fisiológico do animal. O aumento do conteúdo da fibra na dieta tem efeito direto sobre o teor de umidade das fezes, pois em virtude da menor digestibilidade da fração fibrosa, há maior excreção fecal desta fração, o que aumenta tanto a massa fecal quanto o seu teor hídrico. Logo, espera-se aumento do consumo de água quando se tem dieta rica em fibra.

O comportamento ingestivo de novilhas da raça Pantaneira, mantidas em regime de confinamento, não foi influenciado pelos diferentes tipos de fenos utilizados como volumoso. Portanto, é recomendado qualquer um dos tipos de fenos ofertados na dieta de novilhas Pantaneira, adequando-se, assim, às melhores condições de cada produtor.

\section{REFERÊNCIAS}

ALVES, E.M.; PEDREIRA, M.S.; OLIVEIRA, C.A. de; AGUIAR, L.V.; PEREIRA, M.L.A.; ALMEIDA, P.J.P. Comportamento ingestivo de ovinos alimentados com farelo da vagem de algaroba associado a níveis de ureia. Acta Scientiarum, v.32, n.4, p.439435, 2010.
ARNAUD, B.L.; VÉRAS, A.S.C.; FERREIRA, M.A.; SILVA, F.M.; OLIVEIRA, V.; BRASIL, L.H. A.; DE AZEVEDO, M. Efeito da substituição do feno de capim-tifton e do farelo de milho pela palma forrageira e pelo farelo de soja sobre a ingestão de alimentos e parâmetros físiológicos. Acta Science, v. 27 n.4, p.475-482, 2005.

BÜRGER, P.J.; PEREIRA, J.C.; QUEIROZ, A.C.; Comportamento Ingestivo de bezerros holandeses alimentadas com dietas contendo diferentes níveis de concentrado.

Revista Brasileira de Zootecnia, v.29, n. 1, p.236-242, 2000.

CARDOSO, A.R.; CARVALHO, S.; GALVANI, D.B.; PIRES, C.S.; GASPERIN, B.G.; GARCIA, R.P. Comportamento ingestivo de cordeiros alimentados com dietas contendo diferentes níveis de fibra em detergente neutro. Ciência Rural, v.36, n.2, p.604-609, 2006.

CARVALHO, G.G.P.; PIRES, A.J.V.; SILVA, R.R.; RIBEIRO, L.S.O.; CHAGAS, D.M.T. Comportamento ingestivo de ovinos Santa Inês alimentados com dietas contendo farelo de cacau. Revista Brasileira de

Zootecnia, v.37, n.4, p.660-665, 2008.

CARVALHO, G.G.P.; PIRES, A.J.V.; SILVA, R.R.; VELOSO, C.M.; SILVA, H.G.O. Comportamento ingestivo de ovinos alimentados com dietas compostas de silagem de capimelefante amonizada ou não e subprodutos agroindustriais. Revista Brasileira de Zootecnia, v.35, n.4, p.1805-1812, 2006. 
Rev. Bras. Saúde Prod. Anim., Salvador, v.16, n.3, p.688-698 jul./set.., 2015 http://www.rbspa.ufba.br ISSN 15199940 http://dx.doi.org/10.1590/S1519-99402015000300019

CHAGAS, J.C.C. FERREIRA, M. A.; AZEVEDO, M.; SIQUEIRA, M.C.B.; SILVA, A.E.M.; BARROS, L.J.A. Feeding management strategy for sheep in feedlot in hot and humid region. Bioscience Journal, v.31, p.11641173, 2015.

CORREA-CALDERÓN, A.; SANTOS, G. dos; AVENDAÑO, L.; RIVERA, F.; ÁLVAREZ, D.; ARDON, F.; DÍAZ, R. y COLLIER, R. Enfriamento artificial y tasa de concepción de vaquillas Holstein com estrés térmico. Archivos de Zootecnia, v.58, n.222, p.231-239, 2009.

DANI, S.U.; OLIVEIRA, M.V.M. Cattle, Cheese and Conservation. Nature, v.502, p.448, 2013.

DEGASPERI, S.A.R.; COIMBRA, C.H.; PINTÃO, C.T.; SOUZA, F.P.; CHI, K.D.; JUNIOR, P.P.MACEDO, F.Estudo do comportamento de gado Holandês em sistemas de semiconfinamento. Revista Acadêmica de Ciências Agrárias e Ambientais, v.1, n.4, p.41-47, 2003.

FOTIUS, A. C.A.; FERREIRA, M.A.; BISPO, S.V. VERAS, A.S.C.; SALLA, L.E.; CHAGAS, J.C. Behavior of sheep fed different sequences of ingredients in a spineless cactus (Nopalea cochenillifera Salm-Dyck) based-diet.

Revista Brasileira de Saúde e Produção Animal [online], v.15, n.1, p.74-82, 2014.

KEARL, L.C. Nutrient requirements of ruminant sin developing countries. International Feeds tuffs Institute. Lugan: Utah State University, 1982. $381 \mathrm{pp}$.
MAGALHÃES, A. F.; PIRES, A.J.F.; SILVA, F.F. da; CARVALHO, G.G.P. de; CHAGAS, D.M.T.;

MAGALHÃES, L.A. Comportamento ingestivo de ovinos alimentados com cana -de- açúcar ensilada com óxido de cálcio ou ureia. Ciência Animal Brasileira, v.13, n.1, p.57-66, 2012.

MARQUES, J.A.; BARBOSA, O.R.; ALBUQUERQUE, K.P.; NEGRÃO, J.A.; LOBO JUNIOR, A.R.; DOMINGUES, J.S.; PRADO, I.N. Comportamento de novilhas bubalinas terminadas em Comportamento de novilhas bubalinas terminadas em confinamento usando promotor de crescimento ou esferas de chumbo no útero. Acta Science, v.27, n.3, p.363370, 2005.

MIOTTO, F.R.C.; NEIVA, J.N.M.; RESTLE, J.; FALCÃO, A.J.S.; CASTRO, K.J.; MACIEL, R.P. Comportamento ingestivo de tourinhos alimentados com dietas contendo níveis de gérmen de milho integral. Ciência Animal Brasileira, v.15, n.1, p.45-54, 2014.

MISSIO, R.L.; BRONDANI. I. L.; ALVES FILHO, D.C.; SILVEIRA, M.F. da; FREITAS, L. S.; RESTLE, J. Comportamento ingestivo de tourinhos terminados em confinamento, alimentados com diferentes níveis de concentrado na dieta. Revista Brasileira de Zootecnia, v.39, n.7, p.1571-1578, 2010.

MORAIS, J.B.; SUSIN, I.; PIRES, A.V.; MENDES, C.Q.; OLIVEIRA JUNIOR, R.C.; PACKER, I.U. Comportamento ingestivo de ovinos e digestibilidade aparente dos nutrientes de dietas contendo casca de soja.

Pesquisa Agropecuária Brasileira, v.41, n.7, p.111-164, 2006. 
NASCIMENTO, G.V.; CARDOSO, E.A.; BATISTA, N.L. SOUZA, B.B.

CAMBUÍ G.B. Indicadores produtivos, fisiológicos e comportamentais de vacas de leite, Agropecuária Científica do Semiárido, v.9, n.4, p.28-36, 2013.

PINTO, A.P.; MARQUES, J.A.; ABRAHÃO, J.J.S.; NASCIMENTO, W.G.; COSTA, M.A.T.; LUGÃO, S.M.B. Comportamento e eficiência ingestiva de tourinhos mestiços confinados com três dietas diferentes.

Archivos de Zootecnia, v.59, n.227, p.427-434, 2010.

SAENZ, E.A.C. Modelagem da redução do tamanho de partículas na alimentação de ruminantes. Ciência e Agrotecnologia, v.29, n.4, p.886-893, 2005.

SANTOS, S.A.; SILVA, R.A.M.S.; COMASTRI FILHO, J.A.; ABREU, U.G.P.; McMANNUS, C.; MARIANTE, A.S.; LARA, M.A.C.; PELEGRIN, A.O.; RAVAGLIA, E. Desempenho de bezerros pantaneiros, nelore e cruzados criados no Pantanal, Brasil. Archivos de Zootecnia, v.54, n.206-207, p.501-508, 2005.

SILVA, R.R; SILVA, F.F; CARVALHO, G.P. Comportamento ingestivo de novilhas mestiças de holandês x zebu confinadas. Archivos de Zootecnia, v.54, n.205, p.76, 2005.

SILVA, D.J.; QUEIROZ, A.C. de. Análise de alimentos: métodos químicos e biológicos. 3.ed. Viçosa, MG: Universidade Federal de Viçosa, 2002. 235p.
SOUZA, S.R.M.B.O.; ÍTAVO, L.C.V.; RÍMOLI, J.; ÍTAVO, C.C.B.F.; DIAS, A.M. Comportamento ingestivo diurno de bovinos em confinamento e em pastagens. Archivos de Zootecnia, v.56, n.213, p.67-70, 2007.

UNDERSTANDER, D.; MERTENS, D.; THIEX, N. Forage Analyses. Information Systems Division, National Agricultural Library (United States of America) NAL/ USDA, 10301 Baltimore Avenue Beltsville, Md. 2070, 1993.

UNIVERSIDADE FEDERAL DEVIÇOSA - UFV. SAEG - Sistema de análise estatística e genética. Versão 8.0. Viçosa, MG, 2007. 150p.

VALADARES FILHO, S.C.; MAGALHÃES, K.A.; ROCHA JR., V.R. Tabelas brasileiras de composição de alimentos para bovinos. 2.ed. Viçosa, MG: Universidade Federal de Viçosa, 2006. 329 p.

VAN SOEST, P.J. Nutritional ecology of the ruminant. 2.ed. Ithaca: Cornell, 1994.476p.

VAN SOEST, P.J.; ROBERTSON, J.B.; Analysis of forages and fibrous foods. Ithaca, NY: Cornell Universidade, 1985. 202p.

Data de recebimento: $29 / 07 / 2014$

Data de aprovação: 18/08/2015 